\title{
De la participación ciudadana a la escucha social, una perspectiva de los medios públicos de proximidad en Europa
}

\author{
Fernando R. Ojea \\ Secretario General de CIRCOM Regional
}

\section{Referencia de este artículo}

R. Ojea, Fernando (2021). De la participación ciudadana a la escucha social, una perspectiva de los medios públicos de proximidad en Europa. En: adComunica. Revista Científica de Estrategias, Tendencias e Innovación en Comunicación, $\mathrm{n}^{0} 21$, 299-302. DOI: http://dx.doi.org/10.6035/2174-0992.2021.21.16

Para que una democracia sea real es necesario que disponga de una esfera pública. Esa gran plaza virtual en la que se ejerce la comunicación abierta entre los ciudadanos, los sectores privado y público y las autoridades e instituciones gobernantes. Un espacio en el que las personas pueden conversar sobre el mismo tema dentro del mismo marco de tiempo y con un grado comparable de relevancia.

Y para tener una esfera pública que eficazmente puede alcanzar e influir en la toma de decisiones individual, política e institucional, debe ser posible un entorno de desacuerdo constructivo entre actores importantes, ya sean individuos o instituciones. La esfera pública necesita estar basada en la posibilidad sincera y real de visiones cruzadas, movilización de identidades comunes, valores comunes, visiones en conflicto, discusiones, visiones compartidas y compromisos.

Pero es esencial que en esa esfera pública la comunicación fluya en dos direcciones: de los ciudadanos a las autoridades gobernantes y de las autoridades gobernantes a los ciudadanos. Los medios de comunicación son precisamente el elemento que interconecta a los distintos actores de esa conversación pública. Y dentro de ellos debemos resaltar el papel de los medios de servicio público, que están al margen de los intereses comerciales, y más concretamente los medios públicos de proximidad, los más cercanos a la ciudadanía, que en España son representados por las radiotelevisiones autonómicas y en toda Europa se pueden denominar con carácter general como medios públicos regionales. 
Existe una organización que aglutina a los medios públicos audiovisuales y regionales de toda Europa, CIRCOM Regional, presente en treinta países y representativa de 250 estaciones y centros de producción, así como de unos 22.000 periodistas. CIRCOM es, entre otras cosas, un auténtico foro de intercambio de conocimiento y experiencias en estos tiempos de nuevos hábitos entre los usuarios de la comunicación, donde los miembros de esta organización son plenamente conscientes de la importancia de un servicio público independiente y de proximidad que sea útil a las comunidades a las que atienden, ya no sólo mediante la televisión y radio lineales sino cada vez más a través de los medios digitales que permitan llegar al público donde y cuando lo demanda. Los medios que forman parte de CIRCOM son conscientes de su función como intermediario hábil que da voz a los ciudadanos y explica y fiscaliza las acciones políticas y de todo tipo.

La participación ciudadana en los medios públicos no es en si misma una idea nueva, ya que existe un concepto clásico basado en la asistencia a platós y la participación presencial o a distancia en programas (tradicionalmente por teléfono) que puede ser o no en directo. Desde otra perspectiva están en una parte de los medios los sistemas vigentes de defensor del espectador o atención al público, incluyendo a veces la emisión de informes de rendición de cuentas y hasta programas que se emiten en esos mismos medios.

Si vamos a un nivel más avanzado y contemporáneo de participación de la audiencia necesariamente debemos referirnos a la herramienta de las redes sociales, de uso generalizado hoy en día, con sus seguidores, interacción y comentarios, registros individuales en servicios digitales, etcétera. Y hay maneras más estructuradas de participación del público que se manifiestan en diversos países a través de la propia configuración de los órganos de gobierno de los medios públicos, donde se incluye la presencia de organizaciones representativas de la sociedad, pero diferentes de los partidos políticos para contrabalancear los intereses de éstos. En otros casos ese balance social respecto de lo político se recoge en los llamados consejos de audiencias, consejos asesores y fórmulas semejantes.

Desde nuestro conocimiento por la oportunidad de estar en contacto con los medios públicos regionales de toda Europa observamos que, como era de prever, el nivel de implicación en las fórmulas participativas varía según los países, pero podemos fijarnos en los más punteros en este aspecto. Países en los que sobre todo desde el lado informativo ya es más importante la emisión en digital que la convencional, no sólo porque llegan mejor al público, especialmente a través de los dispositivos móviles, sino porque esas comunicaciones desarrollan conversaciones posteriores que forman la larga cola o long tail, que a veces son tanto o más interesantes que las primeras noticias.

Está también la participación del público después de la primera emisión, pues los datos que genera el consumo de estos contenidos en digital si se les hace el se- 
guimiento adecuado ayudan a la toma de decisión de las redacciones para iniciar nuevos trabajos y conocer qué es lo que más interesa. A esto se une la cada vez más frecuente contribución de los ciudadanos para captar sobre todo videos que graban con sus cámaras móviles y luego son recogidos por los medios.

La sensibilidad de los miembros de CIRCOM Regional en este aspecto hace que se considere un valor muy importante la participación del público en la propia concepción de la noticia, reportaje u otra pieza de contenido de la que se ocupa el medio. Muestra de ello es que, en los premios anuales de la televisión pública regional europea, los Prix CIRCOM, desde hace dos años estos elementos de participación ya están explicitados como uno de los criterios del jurado para elegir las mejores producciones europeas.

La tendencia es tan fuerte que incluso se ha abierto en CIRCOM un interesante debate sobre la autoridad del periodista profesional que trabaja para un medio como intérprete único de la actualidad. La cuestión polémica es si deben tener similar reconocimiento iniciativas individuales no profesionales para lanzar informaciones que una vez pasadas por herramientas de comprobación de noticias salen directamente a la esfera pública y no a través de medios de comunicación, a veces con seguimiento masivo únicamente a través del soporte digital ayudado por las redes sociales. Hay países en Europa que son muy flexibles con el concepto de quién puede ejercer como informador y hasta son capaces de reciclar profesionales de otras tareas hacia el periodismo después de darles una formación específica.

Si ampliamos el foco a programas no informativos, precisamente la apertura a la participación del público es uno de los motores que han hecho posible que la emisión en directo se haya convertido en un valor superior de los medios ahora, ya que permite reflejar incluso en la propia pantalla lo que la audiencia está diciendo en cada momento sobre lo que ve, unido a llamadas en el aire (de audio y ahora también de vídeo). El directo como producto periodístico y de entretenimiento ha adquirido un alto valor para generar contenidos más vibrantes y hasta emocionales, y también como elemento diferencial de los medios lineales y de proximidad frente a las poderosas plataformas de videos bajo demanda.

Damos por sentado, por tanto, que la participación ciudadana en sus modalidades modernas ha llegado para quedarse en los medios de servicio público y más en aquellos que tienen vocación de proximidad. Es cuestión de tiempo que los medios o países más rezagados se vayan abriendo a ella en la planificación de sus contenidos y, por qué no, de forma estructural en sus órganos de gobierno.

Y los que ya están incorporando esa participación están lanzando un nuevo concepto, el de la escucha social, que consiste en que el medio se dote de una capacidad organizativa y de las herramientas para seguir lo que dice la sociedad en cada momento y así poder reaccionar rápidamente a sus intereses o demandas. En CIRCOM Regional hemos comenzado a considerar esta actividad dentro de las 
acciones formativas para los miembros de la organización, bajo la certeza compartida de que la escucha social empieza a ser una nueva habilidad de las redacciones más avanzadas y acabará siendo una necesidad para todos los medios públicos de proximidad en Europa. 